\title{
Púrpura Trombocitopénico Idiopático en el niño
}

\author{
Dras. María A. Parga P. ${ }^{1}$, Paola Zolezzi R. ${ }^{2}$ \\ Idiopathic Thrombocytopenic Purpura
}

\begin{abstract}
24 cases of Idiopathic Thrombocy topenic Purpura (ITP) with a total of 30 episodes were teviewed. 19 cases presented a singlo purpuric episode and 5 had a recurrent form.

Eight patients did not take any type of drug. Sixtcen children were treated with steroids; two of them received in addition a different immunosuppressive therapy. One of the latter was submit ted also to splenectomy. Cinical intracranial hemorrhage was not observed.

All the cases reached nornal platelet counts within a variable period ranging from onc week to five months. The follow up had a mean duration of 3 years and 5 months.

Steroid therapy was unnecessarily prolonged in some of the cases. This situation leaded to the adoption of a new schedule for severe cases of JTP, with a total steroid treatment duration of 28 days, with a predetermined dose reduction.
\end{abstract}

El Púrpura Trombocitopénico Idiopático (PTI) en et niño es una enfermedad hemorrágica adquirida que resulta de uná excesiva destrucción de plaquetas. El diagnóstico, en general, es clínico, por exclusión de otras patologías que pueden producir este sindrome ${ }^{1}$. La confirmación debería hacerse por determinación de anticuerpos antiplaquetarios $^{2-3}$.

Esta enfermedad benigna, autolimitada $y$, en general, de corta duración no merecería mayor atención si no fuera por una complicación rara, pero frecuentemente fatal que la ha hecho acreedora de numerosas investigaciones: ha hemorragia intracraneana ( $\mathrm{HIC}$ ). Es así, como, estudiando la patogenia de esta alteración e intentando acortar su curso, se ensayo el tratamiento con corticuesteroides, cuyo uso ha sido muy discutido 4-5-6-7. Actualmente, sin embargo, hay consenso en que este tratamiento debe reservarse para los casos muy sintomáticos y durante cortos períodos ${ }^{7 \cdot 8-9}$.

Frente al dilema del uso de corticoides en el PTl infantil, hemos revisado nuestra experiencia.

\section{MATERIAL Y METODO}

Se analizaron retrospectivamente 19 fichas de pacientes portadores de PTI agudo y 5 de pacientes con PTI recurrente, hospitalizados en el Servicio de Pediatría del Hospital Regional de Valdivia durante el periodo comprendido entre Enero de

\footnotetext{
1 Servicio de Pediatria Hospital Regional de Valdivia.

2 lastituto de Pediatýa, Facultad de Medicina, Universidad Austral de Chile.
}

1975 y Diciembre de 1981 . Se excluyeron de esta revisión los púrpuras neonatales, aquellos secundarios a patología conocida (leucemia, anenia hemolítica, aplasia medular e infecciones) y aquellos que, por alguna razón, no tenían mielograma.

Se consideró PTI agudó al cuadro clíniço que cumple los siguientes requisitos ${ }^{5-10}$ :

Presencia de diátesis hemorrágica.

Trombocitopenia de menos de 6 meses de evolución.

Mielograma compatible con el diagnóstico.

Ausencia de otra patología actual.

Se consideró púrpura recurrente al que presenta trombopenia después de haber alcanzado cifras normales de plaquetas ${ }^{9}$.

A todos los pacientes se les practicó al ingreso hemograma, recuento de plaquetas (en cámara según método de Rees Ecker ${ }^{11}$, Velocidad de Sedimentación (VHS), mielograma, sedimento de orina y, en los niños mayores, células de lupus. Los exámenes hematológicos fueron realizados en el Instituto de Henatología de la Universidad Austral de Chile.

Los pacientes fueron tratados con reposo absoluto durante el periodo sintomático y se transfundió sangre a los que presentaron hemorragias de consideración. Los casos en que se empleó corticoides recibieron Prednisona oral $1 \mathrm{a} 2 \mathrm{mg} / \mathrm{kg}$ de peso/dia o su equivalente por vía parenteral cuando hubo problemas para la administración oral. Este tratamiento se mantuvo hasta la normalización del recuento plaquetario. Una vez obtenido este efecto, la dosis de prednisona se disminuyó gradualmente hasta suprimirla. Se conside ró fracasado el tratamiento esteroidal después de 70 días sin normalización del recuento plaquetario. 


\section{RESULTADOS}

De los niños analizados 5 son de la ciudad de Valdivia y 19 de procedencia rural. La edad de comienzo de los síntomas y el sexo de los pacientes se encuentran en la figura. I. Cinco casos $(20,8 \%)$ corresponden al grupo etario menor de 2 años, de los cuales $3(12 \%)$ son menores de 4 meses.
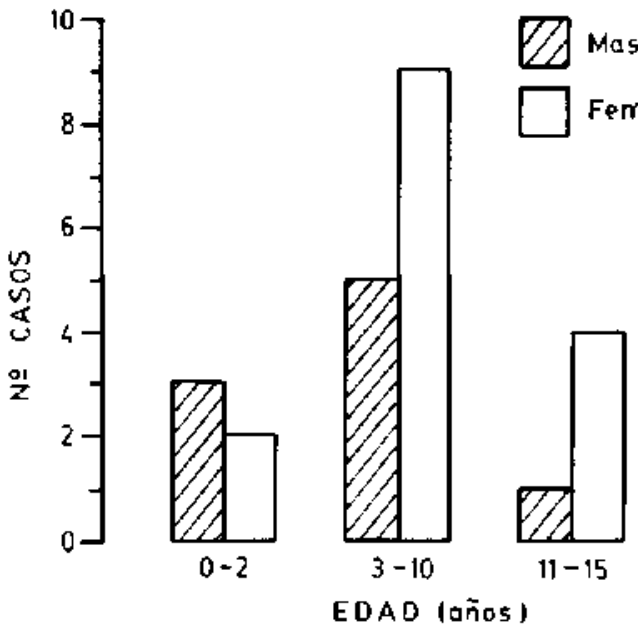

Figura 1.

Edad y sexo en 24 niños con P. T.I.

Cuatro pacientes tuwieron 2 episodios de púrpura y uno presentó 3 , los que se manifestaron entre 2 y 11 meses después de obtenida la remisión del brote anterior, reuniendo así 30 episodios en 24 pacientes. El antecedente de enfermedad aparentemente viral previa se encontró en 10 episodios y no se consignó en 9 .

En la figura 2 se muestran los signos encontrados en los 30 episodios de púrpura. No se observaron casos de hemorragia intracraneana. Una niña de 13 años comenzó, además, con metrorragia importante, signo que no está representado en la figura por ser muy pequeña la proporción de niñas púberes.

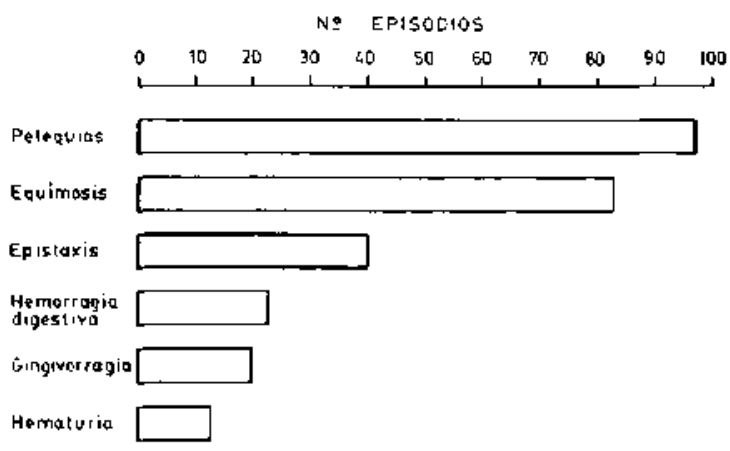

Figura 2.

Signos encontrados en 30 episodios de púrpura en 24 niños con P.T.I.
Analizando los exámenes de laboratorio se observa que 11 episodios de púrpura $(37 \%)$ se acompañaron de anemia (considerando como tal cifras de hemoglobina inferiores a $10 \mathrm{~g}$. \%). El recuento inicial de plaquetas osciló entre $2.000 \mathrm{y}$ $88.000 \times \mathrm{mm}^{3}$ y en 17 episodios de purpura $(57 \%$ ) e] número de plaquetas $\mathrm{x} \mathrm{mm}^{3}$ fue inferior a 10.000. El estudio de células de lupus resultó infructuoso en todos los casos. Con respecto al mielograma todos los pacientes presentaron hiperplasia megacariopoyética, con excepción de uno que tenía megacariopoyesis disminuida pero con aumento de las otras dos series. La serie eritropoyética estaba hiperplástica en el $70 \%$ de los casos en el $83 \%$ hab ia hiperplasia granulopoyética. No se observaron diferencias cuando el mielograma se tomó en la primera o segunda semana de la enfermedad.

Con respecto al tratamiento, recibieron corti coesteroides 16 pacientes de los 24 . El criterio para iniciarlo no fue siempre uniforme. Su duración fue variable, manteniéndose la dosis inicial por un promedio de 26 días, con un rango de 7 a 77 días. El tiempo de reducción de la dosis presenta también una dispersión muy amplia (14 a 90 días con un promeđio de 36 dias). Catorce pacientes no necesitaron otra terapia y entraron en remisión en períodos de una semana a 5 meses del comienzo de la sintomatologia.

Como complicaciones del tratamiento corticoesteroidal se observó hiperfagia, aumento de peso, alteraciones en la distribución de la grasa corporal ( 8 pacientes), acné ( 3 pacientes) y tendencia a la hipertensión en los niños mayores, la que se manejó con régimen hiposódico. En los niños menores se observó aumento de la actividad física e irritabilidad, lo que difícilmente puede atribuirse sólo al uso de esteroides, ya que influyen factores sicológicos derivados de la hospitalización.

Un caso fue tratado con Azatioprina ( $2 \mathrm{mg}$. $x$ $\mathrm{kg} / \mathrm{d}$ ía) una vez que el tratamiento esteroidal se consideró fracasado, respondiendo en forma favoráble a las tres semanas.

Sólo un paciente, una niña de 2 años 8 meses, con PTI recurrente, fue sometida a esplenectomia por la gravedad de sus síntomas y la falta de respuesta al tratamiento esteroidal, obteniéndose un aumento transitorio en el recuento plaquetario, para volver posteriormente a los niveles previos a la operación. En esta niña se ensayó durante un mes tratamiento inmunosupresor con Ciclofosfamida (50 $\mathrm{mg} / \mathrm{d} i \mathrm{a})$ y Vincristina (1 $\mathrm{mg}$. semanal) $)^{9-12}$ sin obtener respuesta, después de lo cual entró en remisión espontánea, la que se ha mantenido hasta ahora.

Ocho pacientes no recibieron tratamiento corticoesteroidal, manteniéndose sólo en reposo y 
observación. En todos se normalizó el recuento de plaquetas antes de 8 semanas de evolucion, sin presentar recidivas posteriores (figura 3 ).

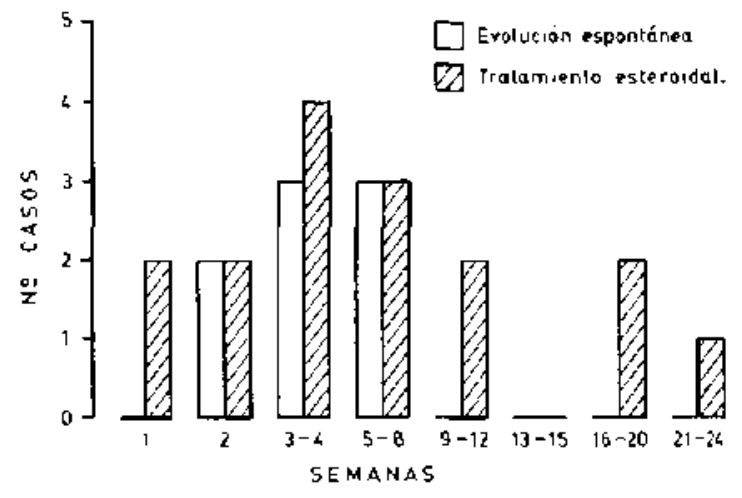

Figura 3.

Notmalización del recucnto plaquetatio en 24 niños con P.T. I.

A todos los pacientes se les ha indicado control periódico en el Policlínico de Hematología de nuestro Hospital. Sin embargo, se han controlado en forma adecuada sólo 12 pacientes de los 24. probablemente debido a la naturaleza benigna de la enfermedad y a factores geograficos y de clima que dificultan el seguimiento. En los casos controlados, por un promedio de 3 años 5 meses, no se ha observado aparición de enfermedades que ptldieran tener relación con el púrpura.

\section{COMENTARIO}

Cuando se analiza el PTI, se encuentran tres formas de evolución descritas clásicamente: aguda, recurrente y crónica, que clínicamente sólo pueden diferenciarse observando su evolución durante un período prolongado. Tomar ${ }^{13}$, estudiando los púrpuras desde el punto de vista inmunológico, encuentra diferencias en la respuesta de los linfocitos a la estimulación con fitohemaglutinina $y$ Lightse ${ }^{3}$ distingue la forma aguda de la crónica cuantificando la inmunoglobulina $G$ adherida a plaquetas. Sin embargo, estas determinaciones no permiten una diferenciación segura en el caso individual ni predecir la evolución recurrente. Como en nuestro hospital no contamos con este tipo de exámenes, nuestros púrpuras son clasificados sólo desde el punto de vista clínico, con seguimiento a través del hemograma. En ellas el mielograma es de uso obligatorio con el objeto de descartar otras patologías.

En nuestra revisión incluimos los púrpura agudos y recurrentes, excluyendo los púrpura crónicos.
La edad de presentación está de acuerdo a lo habitualmente descrito en la literatura. Sin embargo, destaca la presencia de 3 lactantes menores de 4 meses, uno de los cuales presentó un púrpura recurrente. Estos pacientes podrían corresponder a casos de púrpura secundario a infecciones.

Han sido descritos, en la literatura nacional ${ }^{14}$, 14 casos de púrpuras trombocitopénicos entre los 35 y 70 días de vida. En 3 de ellos se confirmó enfermedad de inclusión citomegálica, destacando una al ta incidencia de sindrome semejante a mononucleosis (11 de los 14 casos) y de hepatoesplenomegalia, lo que no se encontró en nuestros pacientes, alejando así la posibilidad que correspondan a infecciones por virus citomegálico.

En los mielogramas sólo cabe destacar además de los megacariocitos elevados, la alta proporción de hiperplasia eritro y granulopoyética. En un caso, el mielograma no es concordante con lo descrito en la literatura 8.10 , encontrándose una megacariopenia que difícilmente puede atribuirse a artefactos de técnica, por tratarse de extendidos de alta densidad celular. El paciente no tenía antecedentes de ingestión de drogas y evolucionó clínicamente como PTI. Ha concurrido en forma regular a control no detectándose, hasta el momento. otra patologia 15.

El punto más discutido en relación al PTl isfantil es el referente al tratamiento estcroidal ${ }^{16}$. Si bien hay acuerdo en mantener una conducta expectantc, en general la discusión se centra en los casus considerados severos, dado el riesgo bajo pero grave, representado por la hemorragia intracraneana. Las publicaciones de casuisticas numerosas ${ }^{4-5.6-8}$ reportan una incidencia de 1 a $2 \%$ de HIC diagnosticada clinicamente. Sin embargo, esta cifra pudiera ser superior si se estudian alteraciones electroencefalográficas y problemas conductuales $y$ de aprendizaje. Mathoth ${ }^{17}$ comunica alteraciones de este tipo en $30 \%$ de sus pacientes portadores de PTI crónico, frecuencia significativamente superior a la encontrada en la población general. Ellos sugieren que estas anomalias pudieran ser secundarias a HIC. subclínicas. lo que no ha sido descrito en relación a pacientes con PTI agudo.

Algunos autores ${ }^{6-8}$ reportan que el riesgo mayor de sufrir una $\mathrm{HIC}$ se presenta en el primer mes de evolución. Sin embargo, Woemer ${ }^{18}$ haciendo una revisión de la literatura reune $\mathbf{1 4}$ casos de $\mathrm{HIC}$ en PTI que se presentaron dentro de los primeros seis meses de diagnosticado el púrpura y en 6 de eltos las HIC se presentaron después del primer mes de evolución. Trece de estos pacientes tenian recuentos plaquetarios inferiores a 10.000 plaquetas por $\mathrm{mm}^{3}$, por lo que de acuerdo con $\mathrm{McClu}$. re ${ }^{7-9}$ correspondian a casos de púrpuras severos, en los cuales se recomendaría tratamiento esteroi- 
dal. El interés radica en que se comunica un caso con un recuento de 20.000 plaquetas por $\mathrm{mm}^{3}$, con un periodo de evolución superior a los dos meses, que hace una HIC masiva que lo conduce a la muerte.

En nuestros pacientes los factores que se consideraron para iniciar tratamiento esteroidal fueron: severidad de las manifestaciones hemorrágicas; recuento plaquetario inferior a $10.000 \times \mathrm{mm}^{3} \mathrm{y}$ presencia de anemia importante.

Consideramos la presencia de anemia como un factor digno de ser tomado en cuenta para iniciar un tratamiento esteroidal debido a que la mayoría de nuestros pacientes provienen de zona rural y suelen ingresar después de dos o más dias de evolución, habiendo presentado algunos de ellos las hemorragias más importantes antes de su ingreso.

De nuestros 16 pacientes tratados con corticoides, 13 cumplían con uno o más de estos requisitos. En 3 casos no hubo justificación para iniciar una terapia esteroidal, excepto que dos de estos pacientes habian sido tratados favorablemente con prednisona en un brote anterior. A su vez, hay 4 casos que, cumpliendo el requisito de tener recuentos plaquetarios muy bajos, no recibieron tratamiento.

Las dosis de corticoides usadas están de acuerdo con to publicado ${ }^{1-5}$, pero el período de administración, en general, fue prolongado, lo que constituye un error. A pesar de esto se observaron pocas manifestaciones clínicas secundarias $y$, en los pacientes controlados, no se han apreciado alteraciones en el ritmo de crecimiento.

Al destacar esta gran variabilidad en la duración del tratamiento con esteroides hemos adoptado el criterio propuesto por Lanzkowsky ${ }^{9}$ quien frente a los PTI en los cuales a la trombopenia unen severas manifestaciones hemorragicas o hay persistencia de síntomas por más de tres semanas, indica un tratamiento esteroidal de 28 dias de duración, empezando con dosis de $60 \mathrm{mg}$. de prednisona diarios ( $40 \mathrm{mg} /$ día para el menor de dos años), que se reducen cada 5 a 7 dias a $40 \mathrm{mg}$., $30 \mathrm{mg}$., $20 \mathrm{mg} ., 10 \mathrm{mg} / \mathrm{d}$ ía interrumpiéndose al finalizar el periodo independientemente de la respuesta obtenida.

\section{RESUMEN}

Se analizaron retrospectivamente 24 pacientes portadores de PTI: 19 agudos y 5 recurrentes con un total de 30 episodios de púrpura. Ocho pacientes no recibieron tratamiento con medicamentos. Dieciséis recibieron corticoides, incluyendo dos que recibieron adicionalmente otra terapia inmunosupresora, extirpándose el bazo a uno de ellos. No hubo casos de hemorragia in tracraneana clínica. Todos los pacientes evolucionaron finalmente hacia la recuperación completa y han sido,controlados por un promedio de 3 años 5 meses.

El tratamiento esteroidal fue innecesariamente prolongado en algunos casos, lo que nos ha llevado a adoptar en los PTl severos un tratamiento de 28 días con plazos fijos de reducción de dosis.

\section{REFERENCIAS}

1 Lighrsey A.L.: Thrombocy topenia in children. Clin. Ped. N.A. 27: 293, 1980 .

${ }^{2}$ Cines D., Schreiber A.: Immune thrombocytopenia. New Engl. J. Med. 300: 106, 1979.

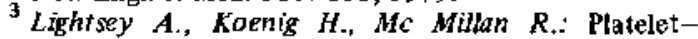
associated immunoglobulin $G$ in childhod idiopathic thrombocy topenic purpura. J. Pediatr. 94: 201, 1979.

${ }^{4}$ Lammi $A_{\text {., Lovric }} V_{\text {.: }}$ Idiopathic thrombocytopenic purpura an epidemiologic study. J. Pediatr. B3: 31, 1973.

5 Simons S., Main Ch. A. Yaish H.M., Rutzky I.: Idiopathic thrombocytopenic purpura in children. $J$. Pediatr. 87: 16,1975 .

${ }^{6}$ Zuelzer $W_{\text {. }}$, Lusher $J_{.}$: Childhood idiopathic thrombocytopenic purpura. Am. J. Dis. Child. 131: 360, 1977.

7 MC Clure P.: Idiopathic thrombocytopenic purpura. Am. J. Dis. Child 131: 357, 1977.

${ }^{3}$ Mc Clure P.: Idiopathic thromcy topenic purpura in children: Diagnosis and management. Pediatries 55: $68,1975$.

9 Lanzkowsky P.: Pediatric Hematology-Oncology. First Ed. 1980. Edit. Mc Graw-Hill, lnc. p. 251.

10 Larrain C. y Fernández H.: Pírpura Trombopénica Idiopática: Análisis clínico y terapeútico de 151 pacientes. Rev. Med. Chile 107: 824, J979.

1 Iavidsohn $I$, Nelson D.A.: The Blood. Platelet count, Clinical Diagnosis by Laboratory Methods. Davidsohn I. y Henry J.B., Eds., W.B. Saunders Company, Filadelfia 158, 1969.

12 Ahn Y.S., Harrington W.J., Seelman R.G., Evtel ChS.: $V$ incristine therapy of idiopathic and secondary thrombocy topenias. New Engl. Med. 291: 376, 1974.

13 Tomar $R$. y Stuart $M$.: Predicting acute vs chronic childhood idiopathic thrombocytopenic purpura. Am. J. Dis. Child. 135: 4481981

14 Taboada H., Campbell M. Osses M., Pruyas, Vergara M.I.: Púrpura trombocitopénica del lactante menor causada por la infección perinatal por citomegalovirus. Bol. Med. Hosp. Infant. 36: 743, 1979.

15 Stoll D.B., Blum S., Pasquale D., Murphy S.: Thrombocytopenia with decreased megakary ocites. Evalua* tion and prognosis. Ann. Int. Med. 94: 170, 1981.

${ }^{16}$ Krivit W. Tate D., White J.G., Robinson L.L.: Idiopathic Thrombocytopenic purpura and intracraneal hemorthage. Pediatrics 67: 570, 1981.

17 Matorh Y., Zaizov R., Fronkel J,J.: Minimal cerebrat dysfunction in children with chronic thrombocy topenia. Pediatrics 47: 698, 1971.

18 Woemer J.S., Abildgagrd $O$., French $B$.: Intracianial hemorrhage in children with idiopathic thrombocytopenic purpura. Pediatrics $67: 453,1981$. 